\title{
Table des matières.
}

1. Le Corbean et le Renard, par La Fontaine pag.

2. Le Chêne et le Roseau, par le même ........ 1

3. Le Laboureur et ses Enfants, par le même . . . . . . 3

4. Petit Pierre, par Boucher de Perthes . . . . . . . . 4

5. Le Montagnard émigré, par Chateaubriand . . . . . . 4

6. Le Colporteur vaudois, par G. de Félice . . . . . . . 6

7. La Mort des Templiers, par Raynouard . . . . . . . 7

8. La Fenille, par Arnault . . . . . . . . . . . . . 9

9. Le Colimaçon, par le même . . . . . . . . . . . . . 9

10. Le Voyageur égaré dans les neiges du Saint-Bernard, par Chênedollé . . . . . . . . . . . . . . . . . 10

11. Le Gland et la Citrouille, par La Fontaine. . . . . . 11

12. Le petit Ecurenil, par Jussieu . . . . . . . . . . 12

13. L'Ange et l'Enfant, par Reboul . . . . . . . . . . 15

14. Souvenirs d'enfant, par F. Béchard. . . . . . . . . 16

15. La Nostalgie, ou la maladie du pays, par Béranger. . . 18

16. Les Hirondelles, par le même. . . . . . . . . . . 20

17. Louis XI., par le même. . . . . . . . . . . . . . 21

18. Les Adieux de Marie Stuart, par le même . . . . . . 23

19. Les Souvenirs du Peuple, par le même . . . . . . . 24

20. La Chute des Feuilles, par Millevoye . . . . . . . . 27

21. Le Nid, par Souvestre . . . . . . . . . . . . . 28

22. Le Soleil, par Lamartine . . . . . . . . . . . . . . . 29

23. L'Etalon, par Rosset . . . . . . . . . . . . . . 30

24. Les quatre Parties du Jour, par Me. A. Tastu . . . . . 32

25. Les Nuages, par van Hasselt . . . . . . . . . . . 33

26. L'Automne, par Lamartine . . . . . . . . . . . . 33

27. L'Arabe au tombeau de son coursior, par Millevoye . . . 35

28. La Voix paternelle, par Foudras . . . . . . . . . . 36

29. Lusignan à sa fille, par Voltaire . . . . . . . . . . 38

30. Le petit Savoyard, par Guiraud . . . . . . . . . . 40

31. Le Moulin de Sans-Souci, par Andrieux . . . . . . . 44

32. Pyrrhus et son confident, par Boileau . . . . . . . . 46 
33. La Mort de Jeanne d'Arc, par Delavigne . . . . . 48

34. La Mort d'Hippolyte, par Racine . . . . . . . . . 50

35. Combat du Cid contre les Maures, par Corneille . . . . 52

36. Songe d'Athalie, par Racine . . . . . . . . . . . 54

37. Trois Jours de Christophe Colomb, par Delavigne. . . . 56

38. Le Gladiateur romain, par Chênedollé . . . . . . . . 58

39. La Grand'mère, par V. Hugo . . . . . . . . . . . . 59

40. Mö̈se sur le Nil, par le même . . . . . . . . . . 61

41. L'Océan, par E. Deschamps . . . . . . . . . . . . . . 64

42. Spectacle alpestre, par E. Naville . . . . . . . . . 66

43. Même sujet, par A. de Flaux . . . . . . . . . . . 67

44. Retour, par A. de Musset . . . . . . . . . . . . 68

45. L'Etoile du Soir, par le même . . . . . . . . . . . 69

46. Le Vase brisé, par Sully Prudhomme . . . . . . . . 70

47. A l'Hirondelle, par le même . . . . . . . . . . . 71

48. Ode sur l'aveuglement des hommes du siècle, par J. B.

Rousseau . . . . . . . . . . . . . . . . . . 72

49. Derniers moments d'un jeune poète, par Gilbert . . . . 74

50. La jeune Captive, par A. Chénier . . . . . . . . . 75

51. Marius dans le marais de Minturnes, par Arnault . . . 77

52. Le Paysan du Danube au sénat romain, par La Fontaine. 79

53. Les Mondes, par de Fontanes. . . . . . . . . . . 81

54. Le Cor, par A. de Vigny . . . . . . . . . . . . 83

55. Mazeppa, par V. Hugo . . . . . . . . . . . . . 86

56. Le Corse, par Barbier . . . . . . . . . . . . . 88

57. Les Catacombes de Rome, par Delille. . . . . . . . 90, 